\title{
Corrosion Inhibition of Bark Extract of Euphorbia royleana on Mild Steel in $1 \mathrm{M} \mathrm{HCl}$
}

\author{
Bishal Thapa1, Dipak Kumar Gupta ${ }^{1,2}$, Amar Prasad Yadav ${ }^{1 *}$ \\ ${ }^{1}$ Central Department of Chemistry, Tribhuvan University, Kirtipur, Kathmandu, Nepal \\ ${ }^{2}$ Department of Chemistry, Tri-Chandra Multiple Campus, Tribhuvan University, Kathmandu, Nepal \\ *Corresponding E-mail: amar2y@yahoo.com \\ (Received: Aug. 26, 2019; Revised: Dec. 24, $2019 \&$ Accepted: Dec. 25, 2019)
}

\begin{abstract}
The bark extract of Euphorbia royleana as a green corrosion inhibitor was studied in $1 \mathrm{M} \mathrm{HCl} \mathrm{using} \mathrm{weight-}$ loss method and potential measurement. The results show that the bark extract of Euphorbia royleana is an effective anti-corrosion inhibitor of mild steel in acidic media. The corrosion rate decreases with the time of immersion. Weight loss experiment shows that the loss in weight decreases with the time of immersion and inhibition efficiency increases with the concentration of extract. It was observed that maximum inhibition efficiency is $99.60 \%$ in $100 \%$ concentration of extract. Potential measurement study shows that bark extracts act as a mixed type of inhibitor i.e. inhibits both anodically as well as cathodically.
\end{abstract}

Keywords: Corrosion inhibitor, Euphorbia royleana, green corrosion inhibitors, inhibition efficiency, OCP

\section{Introduction}

Corrosion is an unavoidable natural phenomenon which is a serious issue and results in a huge impact on the economy [1]. In the UK, the corrosion cost is estimated to be $4-5 \%$ of the Gross National Products (GPS). For most industrialized nations; the average corrosion cost is $3.5-4.5 \%$ [2]. It is estimated that corrosion destroys one-quarter of the world's annual steel production, which corresponds to about 150 million tons per year in this sector [3]. It is estimated that with proper knowledge of corrosion prevention, about 25 to $30 \%$ of this loss can be saved. Several methods can be applied to control corrosion. The use of inhibitors is one of the practical methods for protection against corrosion especially in acid media, to prevent unexpected dissolution and acid consumption $[4,5]$. Unfortunately, the uses of some chemical inhibitors have been limited because their synthesis is very often expensive and they can be toxic and hazardous for human beings environment as well [6]. This has encouraged the search for ecofriendly corrosion inhibitors as an alternative to replace inorganic and organic inhibitors to promote sustainable greenness to the environment. These nontoxic, benign, inexpensive, renewable and readily available alternative corrosion inhibitors have been found in different parts of plant extracts [7].

Natural products obtained from a plant containing alkaloids act as an inhibitor. They are environmentally friendly and economical. Nepal is rich in natural products. Herbs and shrubs are widely spread in nature [8]. As organic corrosion inhibitors are toxic so green inhibitors are of great interest which are biodegradable and do not contain heavy metal and other toxic compounds. Plant extracts can be used to effectively retard the corrosion rate, called the green corrosion inhibitor [9].

Green Inhibitors generally have hetero atoms. O, N and $\mathrm{S}$ are found to have higher basicity and electron density and thus act as corrosion inhibitors. $\mathrm{O}, \mathrm{N}$ and $\mathrm{S}$ are the active centers for the process adsorption on the metal surface. The inhibition efficiency should follow the sequence $\mathrm{O}<\mathrm{N}<\mathrm{S}<\mathrm{P}$. The performance of a green inhibitor is related to the chemical structure and physicochemical properties of the compound like functional groups, electron density at donor atom, $\mathrm{p}$ orbital character and electronic structure of molecule $[1,10]$. The inhibition could be due to adsorption of ions/molecules onto the metal surface, increasing or 
decreasing anodic or cathodic reaction, decreasing the diffusion rate for reactants to the surface of the metal and formation of a protective barrier film $[10,11]$.

\section{Materials and Methods}

\section{Preparation of plant extract}

The Euphorbia royleana (Siudi) plants were collected from Sanothimi, Bhaktapur. The barks of Euphorbia royleana plants were collected and dried in shadow for a month. After that dried barks were finely powdered in a grinder and stored in an air tight plastic jar. $100 \mathrm{~g}$ of dried powder barks of the plant were put into 400 $\mathrm{mL} 1 \mathrm{M} \mathrm{HCl}$ for about 3 days and then refluxed for about 3 hours. Then, the solution was filtered off and then diluted to $250 \mathrm{~mL}$ with $1 \mathrm{M} \mathrm{HCl}$ and marked as $100 \%$ or stock solution. The test media were prepared by diluting the required volume of extract in $1 \mathrm{M} \mathrm{HCl}$. The extract of 10, 20, 30, 40 and $50 \%$ concentration were prepared and $1 \mathrm{M} \mathrm{HCl}$ without extract was taken as control.

\section{Preparation of mild steel specimen}

The mild steel sample was brought from the local market of Balaju, Kathmandu. The sample was cut into average dimensions of $30 \times 30 \mathrm{~mm}$. The samples were polished with silicon carbide paper of 100,400 , $600,800,1000,1200$ and 1500 grits and thoroughly washed with distilled water and ethanol. It is then subjected to a weight loss experiment.

\section{Weight loss experiment}

Samples of size $30 \times 30 \mathrm{~mm}$ were immersed in 50 $\mathrm{mL}$ of different concentration of extracts and in $1 \mathrm{M}$ $\mathrm{HCl}$ as control. Weight loss was determined for one day. MS specimens were also immersed in $50 \mathrm{~mL}$ of $10 \%$ and $1 \mathrm{M} \mathrm{HCl}$ solution for 2, 5 and 7 days. The corrosion rates of the steel were calculated by the following expression.

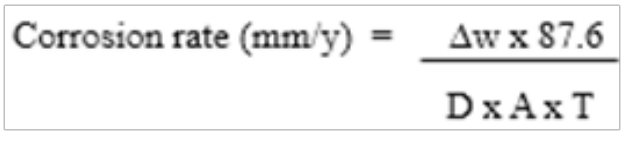

Where,

$\Delta \mathrm{W}=$ weight loss in $\mathrm{mg}$

$\mathrm{D}=$ Density of mild steel in $\mathrm{g} / \mathrm{cm}^{3}$

$\mathrm{A}=$ Area of sample in $\mathrm{cm}^{2}$

$\mathrm{T}=$ Time of exposure in hours
The percentage inhibition efficiency (IE) was determined from

$$
\mathrm{IE} \%=\frac{(\mathrm{W} 1-\mathrm{W} 2)}{\mathrm{W} 1} \times 100
$$

Where, W1 and W2 are weight loss of mild steel in without and with inhibitor solution

\section{Potential measurement}

The mounted and polished specimens were tested for potential measurements. They were immersed in different test media containing $10 \%$ and $100 \%$ concentration of the extracts. The potential was recorded at a day intervals for 2, 3, 4 days' interval for 23 days using a digital multimeter with respect to Saturated Calomel Electrode (SCE), as reference electrode and mild steel specimen as the working electrode. The plot of variation of potential (E) in volt versus SCE with exposure time was plotted.

\section{Results and Discussion}

Variation of weight loss with time of immersion and concentration of bark extract

The weight loss of the mild steel was calculated by the given equation,

Weight loss $\Delta \mathrm{w}=\mathrm{W} 1-\mathrm{W} 2$

Where, W1 and W2 are weight loss of mild steel without and with inhibitor.

The results of the weight loss experiment for mild steel immersed in $1 \mathrm{M} \mathrm{HCl}$ with and without inhibitor were shown in Figure 1. The maximum loss in weight was found in $1 \mathrm{M} \mathrm{HCl}$ without Euphorbia royleana extract throughout the experiment. The addition of Euphorbia royleana extract to the test medium significantly reduced the weight loss. The addition of extract not only decreased the loss in weight but also delayed the action of the test medium. This was because plant extract had adsorbed on the surface of mild steel. It was also observed that loss in weight of mild steel was dependent on the concentration of Euphorbia royleana extract in the test medium. However, the weight loss was increased with increase in time. This may be due to the desorption of inhibitor when the mild steel was exposed for longer period.

It is observed clearly in Figure 2. that the weight loss of mild steel gradually decreases with an increase in 
the concentration of plant extract due to adsorption of inhibitor on the mild steel surface.

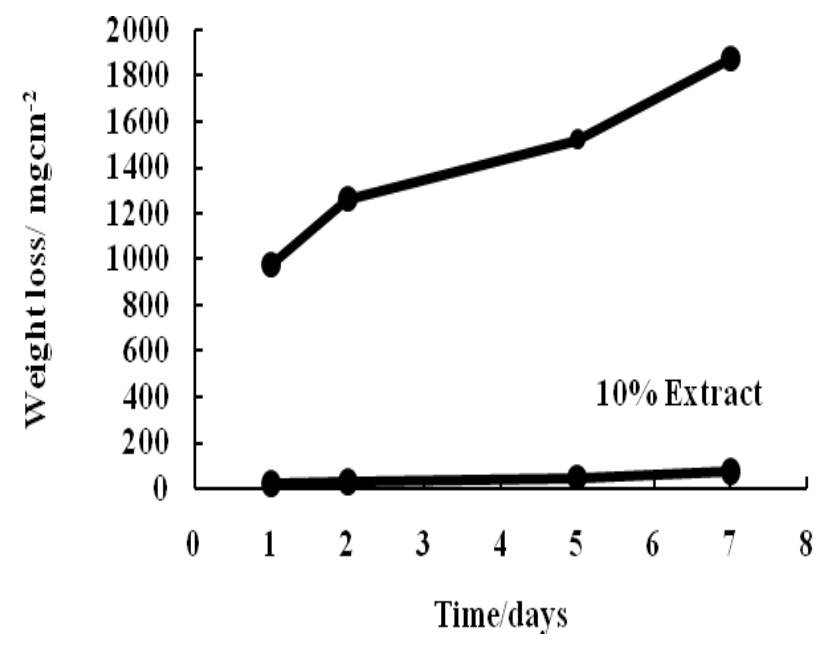

Figure 1: Variation of weight loss with time of immersion

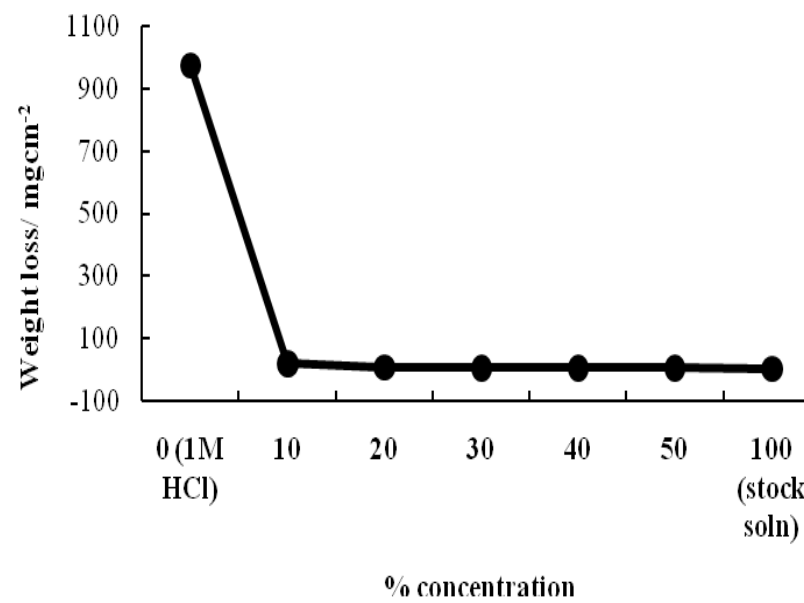

Figure 2: Variation of weight loss with concentration

Variation of inhibition efficiency with concentration of bark extract by weight loss method

Weight loss measurement was carried out for different concentrations of Euphorbia royleana bark extract to study the influence of concentration of extract on the inhibition efficiency for mild steel in $1 \mathrm{M} \mathrm{HCl}$. The inhibition efficiency of the extract on the mild steel increases with an increase in the concentration of the extract which is shown in Figure 3. This is because, as the concentration of the extract increases, the fraction of the surface covered by adsorbed molecule also increases which results in an increase in the inhibition efficiency increases progressively as the concentration of the extract increases up to about $100 \%$ (stock solution). The maximum inhibition efficiency of $99.60 \%$ was achieved.

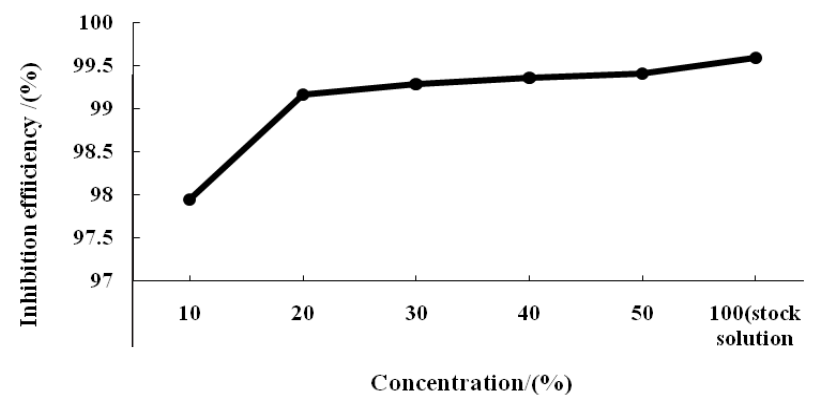

Figure 3: Variation of inhibition efficiency with concentration of extract

Variation of corrosion rate with different concentration of extract and time of immersion

It is clearly seen that the corrosion rate decreases with the increasing concentration of extract as shown in Figure 4.

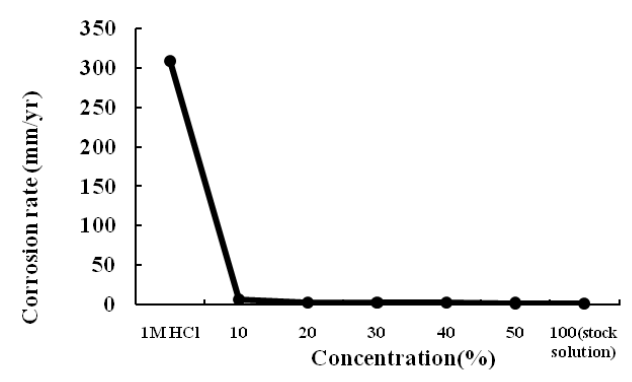

Figure 4: Variation of corrosion rate with concentration of extract

It is also seen that the corrosion rate is high initially which is decreased gradually with the time as shown in Figure 5.

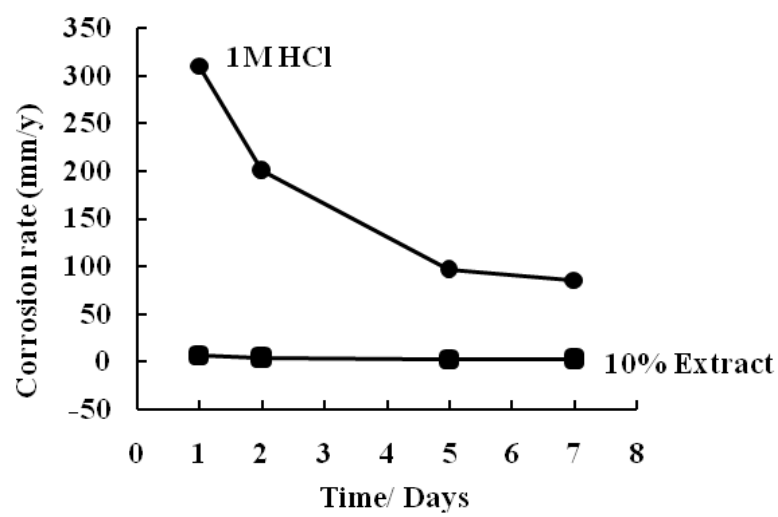

Figure 5: Variation of corrosion rate with time in days 
It may be due to the contamination of corrosion medium with corrosion products or may be due to the deposition of corrosion products on the surface of the steel sample.

These results confirm the good corrosion inhibition of extract towards the corrosion of mild steel in $1 \mathrm{M} \mathrm{HCl}$.

\section{Potential measurement}

OCP or corrosion potential (Ecorr) measurement was carried out using a digital multimeter in reference to Saturated Calomel Electrode (SCE) as a reference electrode. The graph plotted between the potential of mild steel versus time, as shown in fig.6. It was observed that potential shifted towards more positive sharply at first and then decreased slowly and became almost constant with the passage of time for $\mathrm{HCl}$ but for plant extract it was observed that potential shifted to more negative value than that of for $\mathrm{HCl}$ which reveals that sample was cathodically protected i.e. it is due to cathodic inhibition and later again potential shifted positively which shows that sample was anodically protected and then potential became almost constant. Therefore, it reveals that extract was the mixed type of inhibitor [1].

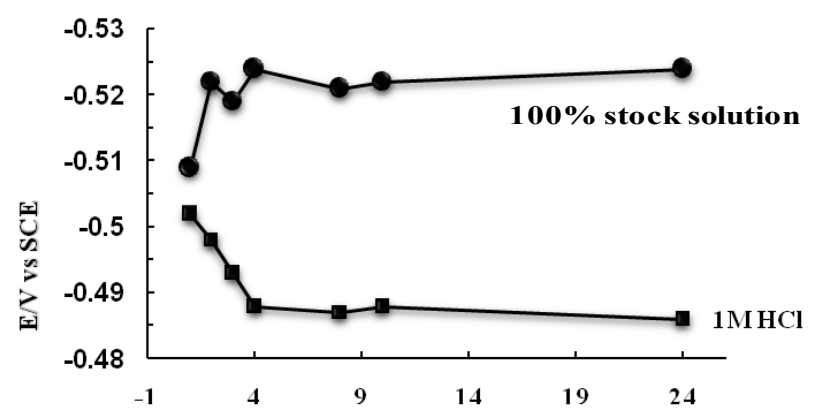

Time /Days

Figure 6: Variation of corrosion potential with time in days

\section{FTIR spectroscopic analysis}

The FTIR spectrum of Euphorbia royleana bark extract was analyzed which is shown in figure 7 , the band at a frequency about $(3500-3200) \mathrm{cm}^{-1}$ is of O-H (3550-3200 $\left.\mathrm{cm}^{-1}\right)$ or of N-H (3500-3300 $\left.\mathrm{cm}^{-1}\right)$ functional group and band at the frequency (17001600) $\mathrm{cm}^{-1}$ is of $\mathrm{C}=\mathrm{O}\left(1750-1680 \mathrm{~cm}^{-1}\right)$. Hence the FTIR studies reveal that the interaction of the inhibitor on the mild steel surface for adsorption in corrosion protection. Thus, the band indicates that there is a lone pair of electron in hetero atom which is responsible for adsorption on metal surfaces.

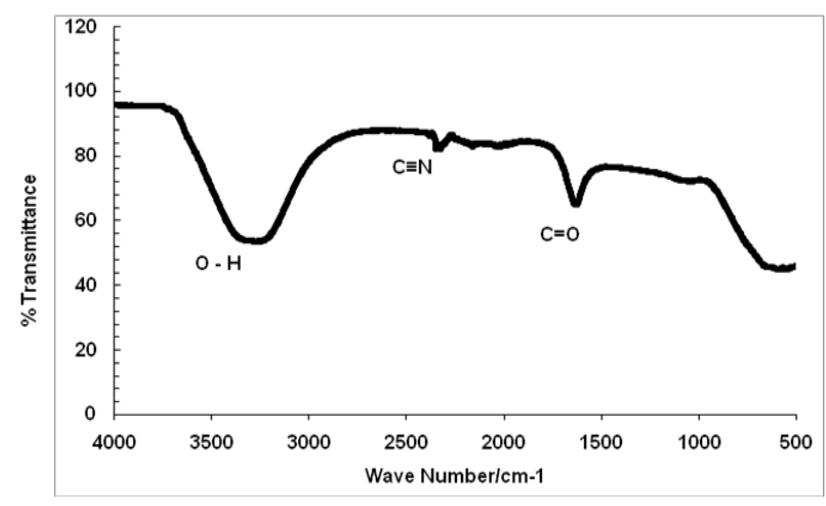

Figure 7: FTIR Spectrum of Extract

\section{Conclusion}

From the above results, the following conclusions can be made.

i. Inhibition efficiency is maximum $(99.60 \%)$ when the mild steel was immersed in $100 \%$ stock solution for 24 hours. Effectiveness of extract towards corrosion is due to the presence of organic compounds that act as inhibiting film forming on the surface of mild steel.

ii. OCP measurement showed that the extract is of mixed inhibitor.

iii. FTIR analysis suggested that the adsorption takes place due to the presence of functional group $\mathrm{O}-\mathrm{H}$, $\mathrm{C} \equiv \mathrm{N}$ and $\mathrm{C}=\mathrm{O}$ group.

\section{Acknowledgements}

Department of Chemistry, Tri-Chandra Multiple Campus is acknowledged for providing necessary laboratory facilities for the experimental work and Central Department of Chemistry, Tribhuvan University, Kathmandu is acknowledged for providing FTIR spectra.

\section{References}

1. M. U. Rahman, S. Gul, M. Umair, A. Anwar and A. K. K. Achakzai, Anticorrosive activity of Rosemarinus officinalis L. leaves extract against mild steel in dilute hydrochloric acid, International Journal Innovative Research in Advanced Engineering (IJIRAE), 2016, 3(3), 3843. 
2. H. H. Uhliq, Corrosion and Corrosion Control, 3rd Ed., John Wiley and Sons, New York, 1985.

3. D. Landolt, Corrosion and Surface Chemistry of Metals, 1st Ed., EPFL press, New York, 2007. (DOI: 10.1201/9781439807880).

4. H. Ashassi-Sorkhabi, B. Shaabani, D. Seifzadeh, Corrosion inhibition of mild steel by some Schiff base compounds in hydrochloric acid, Applied Surface Science, 2005, 239, 154-164. (DOI:10.1016/j.apsusc.2004.05.143).

5. A. K. Satapathy, G. Gunasekaran, S. C. Sahoo, A. Kumar and P. V. Rodrigues, Corrosion inhibition by Justicia gendarussa plant extract in hydrochloric acid solution, Corrosion Science, 2009, 51(12) 2848-2856. ( DOI:10.1016/j.corsci.2009.08.016).

6. J. Halambek, K. Berkovic, J. Vorkapic'-Furac, The influence of Lavandula angustifolia L. oil on corrosion of Al-3Mg alloy, Corrosion Science, 2010, 53, 978-3983.

7. S. A. Umoren, U. M. Eduok, M. M. Solomon, and A. P. Udoh, Corrosion inhibition by leaves and stem extracts of Sida acuta for mild steel in $1 \mathrm{M} \mathrm{H}_{2} \mathrm{SO}_{4}$ solutions investigated by chemical and spectroscopic techniques, Arabian Journal of Chemistry, 2016, 9, 209-224. (DOI:10.1016/j. arabjc.2011.03.008).
8. D. Rawal, J. Sijapati, N. Rana, P. Rana, A. Giri and S. Shrestha, Some high value medicinal plants of Khumbu region Nepal, Nepal Journal of Science and Technology, 2009, 10, 73-82. (DOI:10.3126/ njst.v10i0.2828).

9. P. R. Shrestha, H. B. Oli, B. Thapa, Y. Chaudhary, D. K. Gupta, A. K. Das, K. B. Nakarmi, S. Singh, N. Karki and A. P. Yadav, Bark extract of Lantana camara in $1 \mathrm{M} \mathrm{HCl}$ as green corrosion inhibitor for mild steel, Engineering Journal, 2019, 23(4), 205211.(DOI:10.4186/ej.2019.23.4.205).

10.B.E.AmithaRaniandB.B.J.Bashu, Greeninhibitors for corrosion protection of metals and alloys: an overview, International Journal of Corrosion, 2012, 2012. ( DOI:10.1155/2012/380217).

11. D. Ben Hmamou, R. Salghi, L. Bazzi, B. Hammouti, S. S. Al-Deyab, L. Bammoul, L. Bazzi and A. Bouyanzer, Prickly pear seed oil extract: A novel green inhibitor for mild steel corrosion in $1 \mathrm{M} \mathrm{HCl}$ solution, International Journal of Electrochemical Science, 2012, 7, 1303-1318. 